\title{
Data processing in FTIR imaging of cells: Towards protein secondary structure imaging
}

\author{
Erik Goormaghtigh *, Allison Derenne, Audrey Bénard, Régis Gasper and Vincent Raussens \\ Laboratory for the Structure and Function of Biological Membranes, Center for Structural Biology and \\ Bioinformatics, Université Libre de Bruxelles, Brussels, Belgium
}

\begin{abstract}
Focal plane arrays provide a rapid method for infrared imaging of cells and tissues. Beside statistical analyses designed to classify image features, insight into the structure of the molecules present in the sample can be obtained. The paper presents a simple way to retrieve complete information on protein secondary structure from the thousands of spectra obtained by imaging. Human PC-3 prostate cancer cells were shown here to present cell-to-cell variations in protein secondary structure which might be related to the cell cycle. Intracellular variations are small but intercellular variations can be quite significant. This observation could yield unanticipated insight in cell population analysis. Furthermore, the results demonstrate the robustness of secondary structure determination on individual pixels at a sub-cellular scale.
\end{abstract}

Keywords: IR spectroscopy, cancer, IR imaging, prostate PC-3 cells

\section{Introduction}

Focal plane arrays (FPA) provide a rapid method for infrared imaging of cells and tissues. High quality spectra can be acquired in a few minutes but the amount of data (e.g., 4096 spectra every 5 min for a $64 \times 64$ FPA) requires automatized processing in order to extract significant information from this large quantity of data. We have set up a software designed to perform the necessary pre-processing which includes subtraction of water vapor contribution, baseline correction, scaling and derivative computation when required. Baseline subtraction and scaling are necessary to compare small differences in the shape of the spectra. Indeed, in the absence of processing, good images are obtained but essentially provide information on the thickness of the sample rather than on the nature or conformation of the molecules present in the cells. To be significant, the quality of the raw data also needs to be evaluated. The software computes for every pixel of the infrared image the noise in the $2000-1900 \mathrm{~cm}^{-1}$ region and the intensity of the signal in the protein amide I band. In turn, spectra with signal-to-noise ratio below a defined threshold can be identified and handled appropriately. Beside usual statistics required for cell classification, further computation can be achieved to provide information on the secondary structure of the proteins present in the sample. The infrared spectrum of protein is indeed strongly related to the protein secondary structure content $[4,5,7]$. The present paper focuses on secondary structure determination applied to every pixel (spectrum) of the image. Human PC-3 prostate cancer cells studied earlier by conventional FTIR [2] were shown here to present cell-to-cell variations in protein secondary structure which might be related to the cell cycle.

\footnotetext{
* Corresponding author: Dr. Erik Goormaghtigh, Laboratory for the Structure and Function of Biological Membranes, Center for Structural Biology and Bioinformatics, Campus Plaine CP206/02, Université Libre de Bruxelles, Bld du Triomphe 2, CP206/2, B1050 Brussels, Belgium. Tel.: +32 265053 86; Fax: +32 265053 82; E-mail: egoor@ulb.ac.be.
} 


\section{Materials and methods}

\subsection{Cell culture and treatment}

The human prostate cancer PC-3 (CRL-1435) cell line was obtained from the American Type Culture Collection (ATCC, Manassas, VA, USA) and was maintained according to the supplier's instructions. The cells were incubated at $37^{\circ} \mathrm{C}$ in sealed (airtight) Falcon plastic dishes (Nunc, Invitrogen SA, Merelbeke, Belgium) in a humidified atmosphere of $5 \% \mathrm{CO}_{2}$. The cells were kept in exponential growth in RPMI medium supplemented with $10 \%$ fetal bovine serum, $1 \%$ penicillin/streptomycin as antibiotic/antimycotic, and $1 \%$ kanamycin to prevent mycoplasms. Cell culture medium and serum were purchased from Gibco (Invitrogen, Merelbeke, Belgium). Penicillin/strepromycin and kanamycin solutions were provided by Sigma-Aldrich SA (Bornem, Belgium).

For FTIR spectroscopy, cells were detached by means of a five-minute treatment with trypsin/EDTA buffer (Gibco, Invitrogen SA, Merelbeke, Belgium). The reaction was stopped by adding $1 \mathrm{ml}$ of culture medium. The cells were pelleted by a 2-minute centrifugation $(300 \mathrm{~g})$, and washed three times in isotonic solution $(\mathrm{NaCl}, 0.9 \%)$ to ensure complete removal of trypsin and culture medium.

\subsection{FTIR spectroscopy}

$0.5 \mu \mathrm{l}$ of cell pellet re-suspended in about $10 \mu \mathrm{l} 0.9 \% \mathrm{NaCl}$ was deposited on $\mathrm{BaF}_{2}$ window. Then, the sample was quickly evaporated under a $\mathrm{N}_{2}$ flow. The IR data were collected using a Hyperion 3000 IR imaging system (Bruker Optics, Ettlingen, Germany), equipped with a $64 \times 64$ Mercury Cadmium Telluride (MCT) Focal Plane Array (FPA) detector. The data were collected in transmission mode. $64 \times$ 64 pixels (spectra) were recorded at a magnification of $15 \times$ on a $2560 \times 2560 \mu^{2}$ detector. In turn, the size of the image was $170 \times 170 \mu \mathrm{m}^{2}$ and the pixels were $2.7 \times 2.7 \mu \mathrm{m}^{2}$ each. The spectral resolution was set to $8 \mathrm{~cm}^{-1}$ and data were encoded every $1 \mathrm{~cm}^{-1}$ between 3800 and $900 \mathrm{~cm}^{-1}$. One IR image resulted in 4096 spectra, each one being the average of 256 scans (ca 5 min recording). All the spectra were pre-processed as follows. The water vapour contribution was subtracted as described previously [3,6] with 1956-1935 $\mathrm{cm}^{-1}$ as reference peak. The spectra were then normalized for equal area between 1725 and $1481 \mathrm{~cm}^{-1}$ after subtraction of a straight baseline passing by these two points. Spectra were then rescaled so that the area between the spectrum and a baseline drawn between the spectrum points at 1725 and $1481 \mathrm{~cm}^{-1}$ was 10,000 [4]. Finally, spectra were retained for further analysis when the signal-to-noise ratio was better than 450:1. This ratio was calculated using the maximum found in the $1750-1480 \mathrm{~cm}^{-1}$ spectral range for signal and the standard deviation in the $2000-1900 \mathrm{~cm}^{-1}$ region for noise determination. $\beta$-turn content was evaluated as $\beta$-turns $(\%)=-14.25+0.36 \mathrm{~A}^{1678}+0.85 \mathrm{~A}^{1501}$ where $\mathrm{A}^{1678}$ and $\mathrm{A}^{1501}$ refer to the absorbance at 1678 and $1501 \mathrm{~cm}^{-1}$, respectively [4].

The processing of the spectra was carried out by means of specific software generated in our lab running under Matlab (Mathworks Inc.).

\section{Results and discussion}

Figure 1 reports the analysis of a spread of PC-3 human prostate cancer cells on a $\mathrm{BaF}_{2}$ window. The visible image (Fig. 1A) indicates the presence of distinct cells separated by area without cells. The imaging focal plane array system provides 4096 FTIR spectra simultaneously and allows every cell to be covered by about 20-30 pixels. Contribution of water vapor was subtracted as described in Section 2. 
After baseline correction and scaling of the spectra, the secondary structure of the proteins was calculated for every pixel of the image (representing about $40 \times 10^{-15} \mathrm{~g}$ of protein, see [4]). The $\beta$-turn content was plotted in Fig. 1, panel B. Interestingly, the secondary structure varied from cell to cell but was rather homogenous within each cell. Two cells with low $\beta$-turn content (ca 13\%) (labeled \#1 and 2) and two cells with high $\beta$-turn content (ca 17\%) (labeled \#3 and 4) were selected as indicated on panel B. All the spectra from the pixels covering these 4 cells were collected. In a first step, the average spectrum for each cell was computed. The 4 average spectra are presented in panel C. A slight difference in the shape and position of the maxima of Amide I can be observed between the mean spectra of cells \#1 and 2 on the one hand and mean spectra of cells \#3 and 4 on the other hand. These differences are better
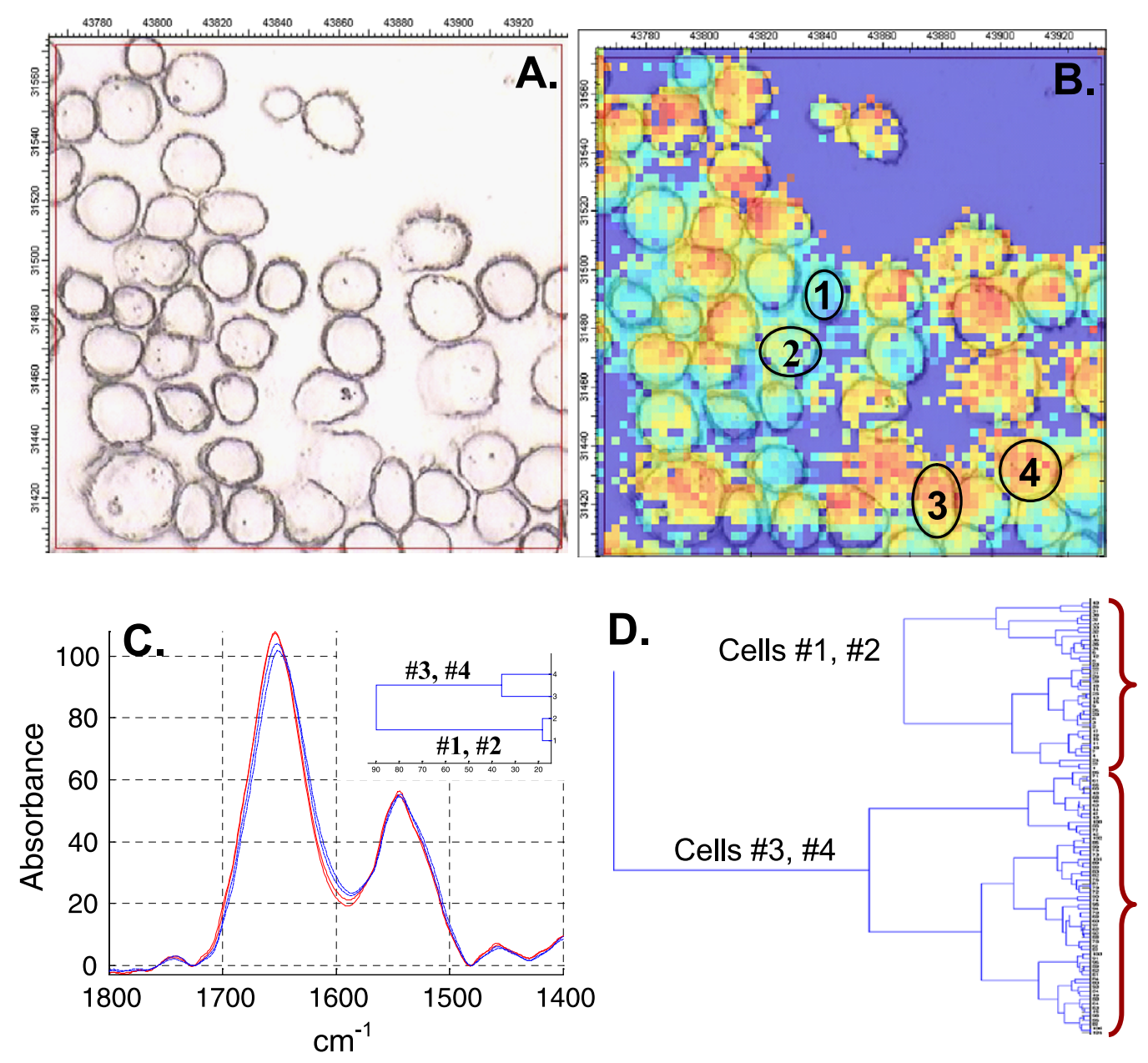

Fig. 1. (A) Visible image $\left(170 \times 170 \mu \mathrm{m}^{2}\right)$ of a smear of prostate PC-3 cancer cells. (B) The same microscopic field recorded by infrared imaging and processed as described in the text. Pixel size is $2.7 \times 2.7 \mu \mathrm{m}^{2}$. The $\beta$-turn content computed as described in the text is presented and varies from $13 \%$ (light blue) to $17 \%$ (red). Two cells numbered \#1 and 2 have a relatively low $\beta$-turn content while cells numbered \#3 and 4 have a higher $\beta$-turn content. A blue color was used where the signal-to-noise was $<450$. The mean spectra for all the spectra coming from each of the 4 cells identified on panel B are reported on panel $\mathrm{C}$ between 1800 and $1400 \mathrm{~cm}^{-1}$. The dendrogram (Euclidian distance, Ward linkage, 1700-1500 $\mathrm{cm}^{-1}$ range) was built to classify the 4 mean spectra. Panel D illustrates the classification of all the individual spectra belonging to the 4 cells identified in panel B (Euclidian distance, Ward linkage, $1700-1500 \mathrm{~cm}^{-1}$ range). 
illustrated on the dendrogram presented in panel C (inset). Clearly, on the average, cells \#1 and 2 are very similar but significantly different from the cells \#3 and 4. In order to address the question of the distribution of the secondary structures in individual pixels for the 4 cells, a new dendrogram was built using all the spectra collected (Fig. 1, panel D). Amazingly, two main clusters were evidenced with every single pixel coming from cells \#1 and 2 belonging to the first cluster and every pixel from cells \#3 and 4 to the second one. This result demonstrates both the robustness of secondary structure determination on individual pixels and the homogeneity of the individual cells. It must be noted that because of the relatively poor spatial resolution, within cell large heterogeneity is not expected to be measured.

The biological significance of the differences observed between cells is difficult to assess. The shift observed in the maximum of the Amide I band is reminiscent of the shifts observed in second derivative spectra of HeLa cells when going from G1 phase to S or G2 phase [1]. It can therefore be hypothesized that secondary structure allows the differentiation of cells according to the cell cycle phase.

In conclusion, structural analysis of proteins at a sub-cellular scale is possible. Intracellular variations are small but intercellular variations can be quite significant and could yield unanticipated insight in cell population analysis.

\section{Acknowledgements}

This research has been supported by a grant from Interuniversity Attraction Poles (IAP) P6/19 (Belgium) and the National Fund for Scientific Research (FRFC 2.4533.10 and 2.4588.06). Erik Goormaghtigh and Vincent Raussens are respectively Director of Research and Senior Research Associate with the "National Fund for Scientific Research", Belgium. Allison Derenne and Audrey Bénard are supported by the FRIA (Belgium).

\section{References}

[1] S. Boydston-White, M. Romeo, T. Chernenko, A. Regina, M. Miljkovic and M. Diem, Cell-cycle-dependent variations in FTIR micro-spectra of single proliferating HeLa cells: Principal component and artificial neural network analysis, Biochim. Biophys. Acta 1758 (2006), 908-914.

[2] R. Gasper, J. Dewelle, R. Kiss, T. Mijatovic and E. Goormaghtigh, IR spectroscopy as a new tool for evidencing antitumor drug signatures, Biochim. Biophys. Acta 1788 (2009), 1263-1270.

[3] E. Goormaghtigh, FTIR data processing and analysis tools, in: Advances in Biometrical Spectroscopy, Vol. 2, A. Barth and P.I. Haris, eds, IOS Press, Amsterdam, 2009, pp. 104-128.

[4] E. Goormaghtigh, R. Gasper, A. Benard, A. Goldsztein and V. Raussens, Protein secondary structure content in solution, films and tissues: Redundancy and complementarity of the information content in circular dichroism, transmission and ATR FTIR spectra, Biochim. Biophys. Acta 1794 (2009), 1332-1343.

[5] E. Goormaghtigh, V. Raussens and J.M. Ruysschaert, Attenuated total reflection infrared spectroscopy of proteins and lipids in biological membranes, Biochim. Biophys. Acta 1422 (1999), 105-185.

[6] E. Goormaghtigh and J.M. Ruysschaert, Subtraction of atmospheric water contribution in Fourier transform infrared spectroscopy of biological membranes and proteins, Spectrochim. Acta 50A (1994), 2137-2144.

[7] E. Goormaghtigh, J.M. Ruysschaert and V. Raussens, Evaluation of the information content in infrared spectra for protein secondary structure determination, Biophys. J. 90 (2006), 2946-2957. 


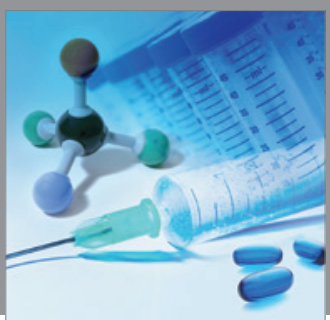

International Journal of

Medicinal Chemistry

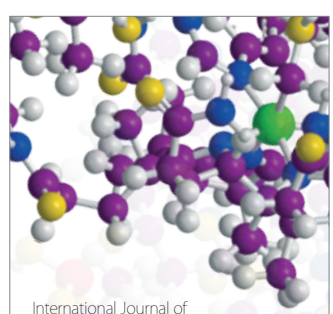

Carbohydrate Chemistry

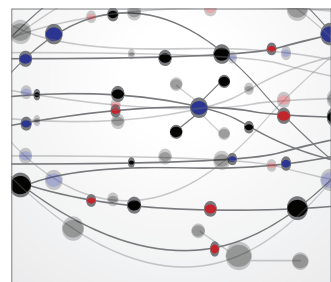

The Scientific World Journal
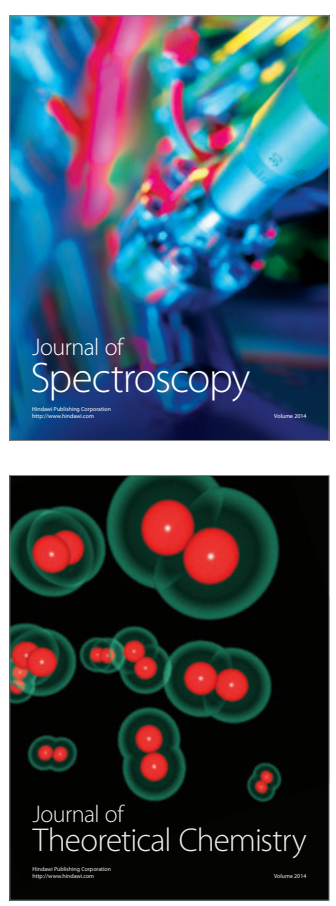
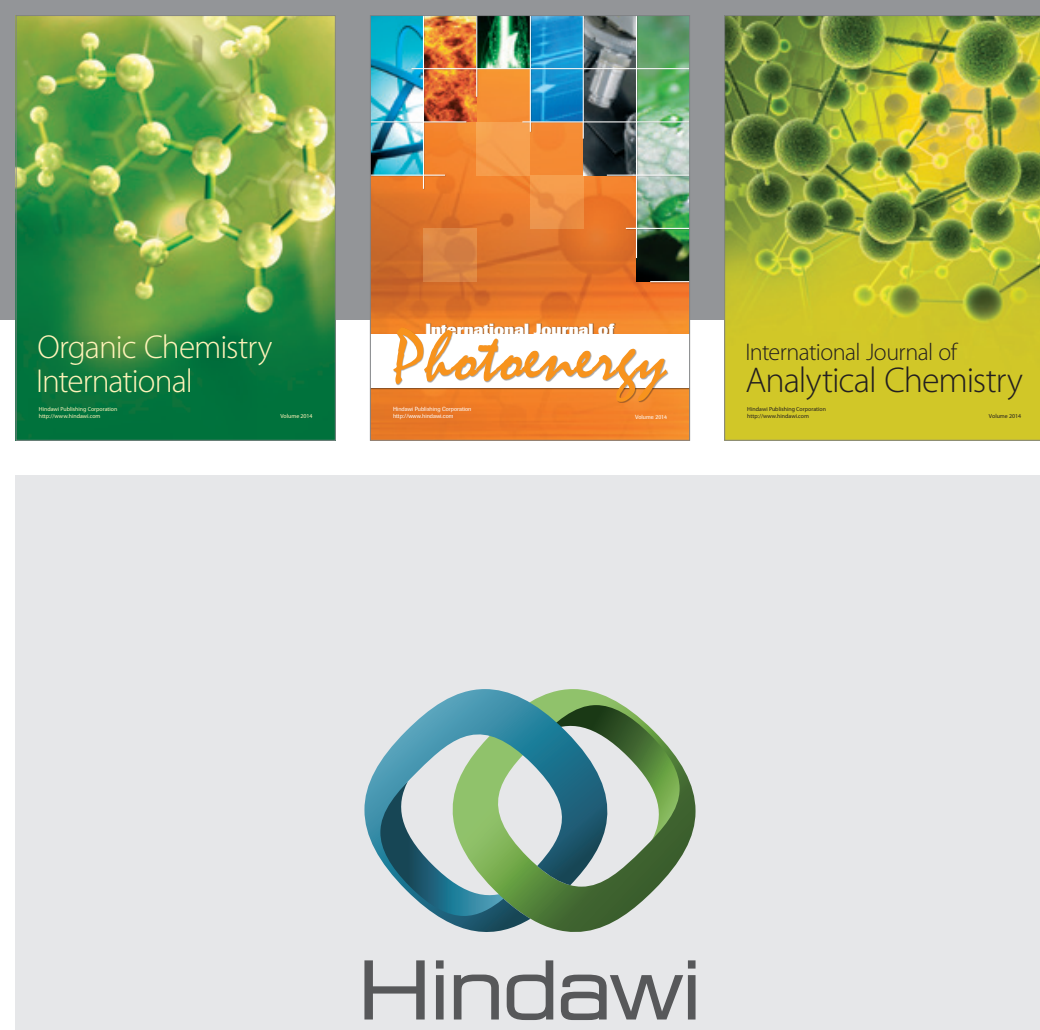

Submit your manuscripts at

http://www.hindawi.com
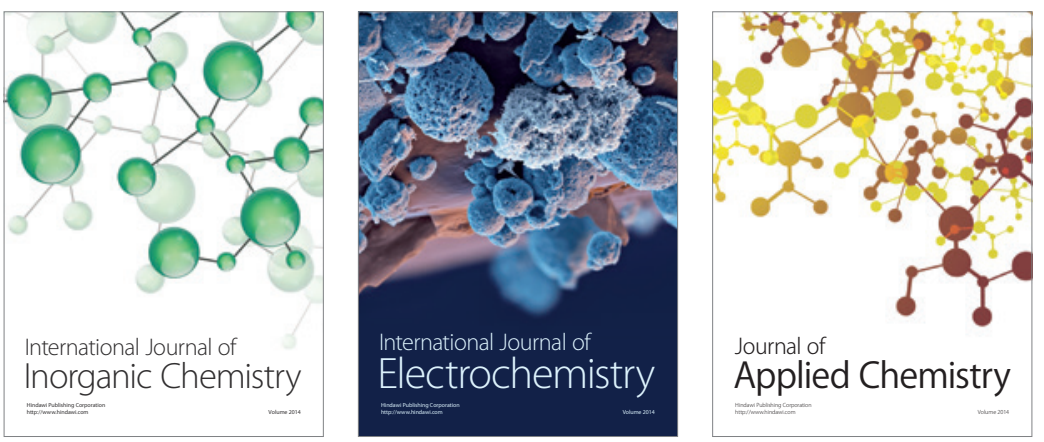

Journal of

Applied Chemistry
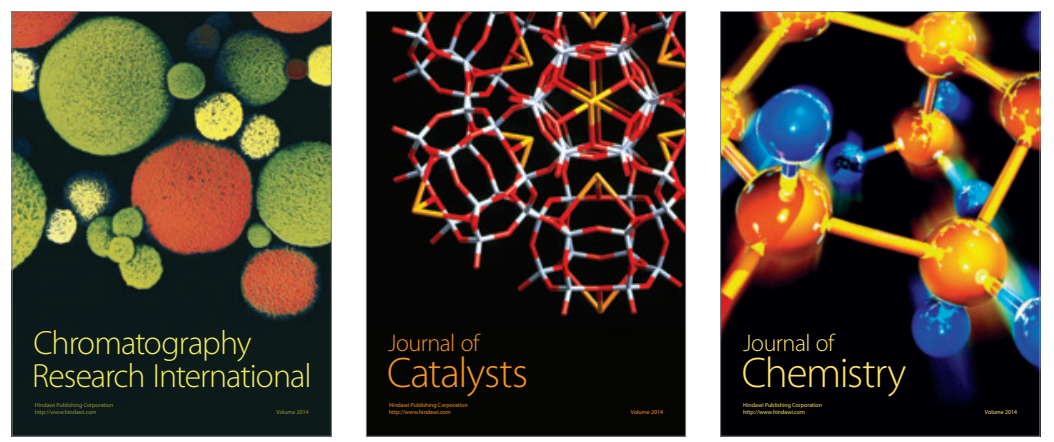
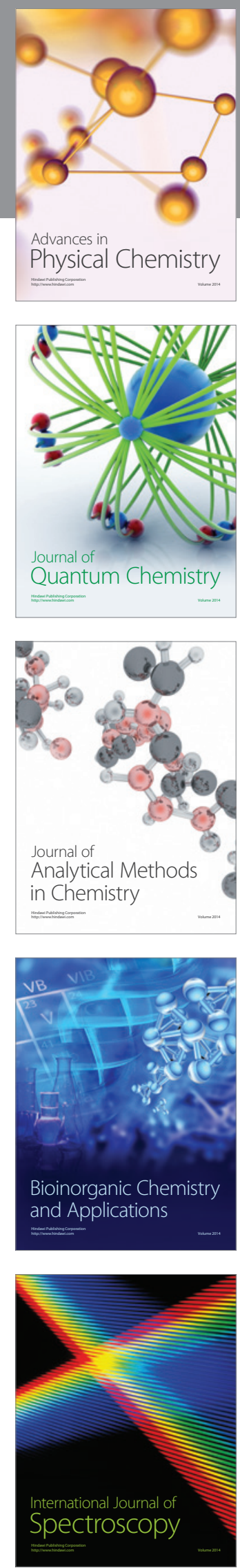